\title{
Composite split cord malformation associated with a dermal sinus tract, dermoid cyst, and epidural abscess: A case report and review of literature
}

Saad Akhtar

Aga Khan University, saad.akhtar@aku.edu

Abdul Azeem

Aga Khan University

Muhammad Shahzad Shamim

Aga Khan University, shahzad.shamim@aku.edu

Muhammad Zubair Tahir

Great Ormond Street Hospital, London, UK.

Follow this and additional works at: https://ecommons.aku.edu/pakistan_fhs_mc_surg_neurosurg

Part of the Neurology Commons, Neurosurgery Commons, and the Surgery Commons

\section{Recommended Citation}

Akhtar, S., Azeem, A., Shamim, M., Tahir, M. Z. (2016). Composite split cord malformation associated with a dermal sinus tract, dermoid cyst, and epidural abscess: A case report and review of literature. Surgical Neurology International, 7, 43.

Available at: https://ecommons.aku.edu/pakistan_fhs_mc_surg_neurosurg/217 


\title{
Composite split cord malformation associated with a dermal sinus tract, dermoid cyst, and epidural abscess: A case report and review of literature
}

\author{
Saad Akhtar, Abdul Azeem¹ ${ }^{1}$ Muhammad Shahzad Shamim, Muhammad Zubair Tahir ${ }^{2}$ \\ Department of Surgery, Section of Neurosurgery, Aga Khan University Hospital, ${ }^{1}$ Medical College, Aga Khan University, Karachi, Pakistan, \\ ${ }^{2}$ Department of Neurosurgery, Great Ormond Street Hospital, London, UK \\ E-mail: Saad Akhtar - saad.akhtar@aku.edu; Abdul Azeem - abdulazeem22@hotmail.com;*Muhammad Shahzad Shamim -shahzad.shamim@aku.edu; \\ Muhammad Zubair Tahir - zubair.tahir@gosh.nhs.uk \\ *Corresponding author \\ Received: 09 February 16 Accepted: 14 March 16 Published: 19 April 16
}

\begin{abstract}
Background: Split cord malformation (SCM) is typically present at a single level but rarely, may be present at multiple levels in the spinal cord and can be associated with a wide array of lesions such as myelomeningoceles, lipomas, teratomas, and dermal sinus tracts (DSTs).

Case Description: We describe a case of a 15-month-old female child who presented with high-grade fever and progressive motor weakness in the lower limbs. Magnetic resonance imaging revealed the presence of SCM along with an epidural abscess, DST, and dermoid cyst. The child underwent surgery for excision of DST along with removal of the dermoid cyst and drainage of epidural abscess. The postoperative course was uneventful. Elective repair of the SCM was performed 4 weeks later. The postoperative course was uneventful again.

Conclusion: To the best of our knowledge, the combination of a composite SCM with a DST and dermoid cyst with associated epidural abscess has rarely been reported in literature.
\end{abstract}

Key Words: Dermal sinus tract, dermoid cyst, empyema, split cord malformation

\begin{tabular}{l}
\hline Access this article online \\
\hline Website: \\
www.surgicalneurologyint.com \\
\hline DOI: \\
10.4103/2152-7806.180764 \\
\hline Quick Response Code:
\end{tabular}

\section{INTRODUCTION}

Split cord malformation (SCM) has been classified by Pang et al., into Types 1 and 2. ${ }^{[14,15]}$ Type 1 SCM is defined by the presence of two hemicords, each in their own dural tube and separated by a dura-sheathed rigid osseocartilaginous median septum or bony spur; whereas Type 2 SCM refers to the presence of two hemicords within a single dural tube separated by a nonrigid, fibrous median septum. ${ }^{[14,15]}$

Congenital dermal sinus tract (DST) formation is an anomaly resulting from the abnormal separation of the neuroectoderm from the cutaneous ectoderm. ${ }^{[10]}$ The sinus can terminate in subcutaneous tissue, or it may extend beyond the dura and terminate in the spinal cord or conus medullaris. ${ }^{[9]}$ This allows a path for infections and hence the formation of an abscess. ${ }^{[5]}$ DSTs may also be associated with inclusion cysts which may be "intramedullary, intradural extramedullary, or extraspinal in location." "[4]

This is an open access article distributed under the terms of the Creative Commons Attribution-NonCommercial-ShareAlike 3.0 License, which allows others to remix, tweak, and build upon the work non-commercially, as long as the author is credited and the new creations are licensed under the identical terms.

For reprints contact: reprints@medknow.com

How to cite this article: Akhtar S, Azeem A, Shamim MS, Tahir MZ. Composite split cord malformation associated with a dermal sinus tract, dermoid cyst, and epidural abscess:A case report and review of literature. Surg Neurol Int 2016;7:43. http://surgicalneurologyint.com/Composite-split-cord-malformation-associatedwith-a-dermal-sinus-tract,-dermoid-cyst,-and-epidural-abscess:-A-case-report-andreview-of-literature/ 
The combination of Type 1 SCM with associated anomalies has been reviewed in literature; however, to the best of our knowledge, a combination of SCM at various levels in continuation with DST and dermoid cyst has rarely been reported. This case report also reviews the relevant literature related to this presentation.

\section{CASE REPORT}

A 15-month-old female child presented with high-grade fever and progressive bilateral leg weakness with difficulty in balance for 2 weeks. There was no history of trauma, and the birth history was unremarkable. The patient was the first child of consanguineous parents.

On clinical examination, power in the left lower limb was $3 / 5$ and $4 / 5$ in the right lower limb. Examination of the back revealed a very small, abnormal tuft of hair in the midline in the mid lumbar region suggesting the presence of occult spinal dysraphism [Figure 1]. Thorough examination of the tuft of hair did not reveal any apparent sinus opening.

Magnetic resonance imaging (MRI) of the brain and full spine was carried out which revealed the presence of two Type I SCM in the thoracolumbar regions. The malformation started as a Type I SCM from T4 to T6, separated by a bony spur. The two hemicords then entered the same dural sheath but before uniting into a

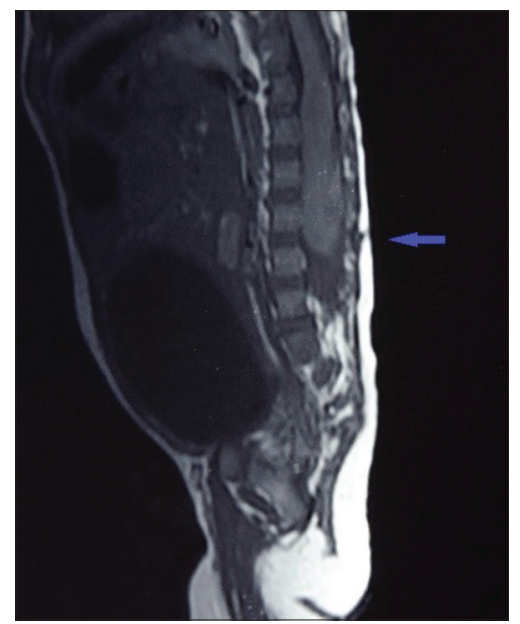

Figure I: TI-weighted image (sagittal section) with the dermal sinus tract (pointed by the blue arrow) single, normal spinal cord, divided into another Type 1 SCM from T9 to T1l, separated by another bony spur. The two hemicords then fused into a single dural sheath before continuing as a single spinal cord from T12 onward [Figure 2]. The MRI also showed a DST at Ll [Figure 1] and an epidural abscess from T12 to L3 level [Figure 3]. Preoperative workup revealed C-reactive protein (CRP) of 2.8. The child was also evaluated for other anomalies, and computed tomography scan of kidney, ureter, and bladder revealed a duplicate collecting system with two separate renal pelvises and ureters in the right kidney.

The child underwent surgery through a limited exposure, incorporating the tuft of hair. Upon dissecting the lumbar fascia, a thick-walled, pearly white, elongated sinus tract was soon visible [Figure 4]. The tract was traced to the dura, where it fused onto it, communicating directly with the intradural space. The entire tract was excised, including the attached dura of the thecal sac, which was then primarily repaired. The extradural space showed extensive purulent collection along with long $(2-3 \mathrm{~cm})$ strands of thick hairs and sebaceous material. The extradural space was further explored through one level laminectomy and was extensively irrigated until the irrigant appeared clear and no further hairs could be delivered. The DST and dermoid cyst were distant from either of the SCM. Samples were sent for culture, sensitivity, and histopathological analysis. No attempts were made to relieve the SCM at this stage.

Culture from the pus showed growth of Staphylococcus aureus which was also resistant to all beta-lactams. Histopathology revealed a sinus tract with collagenous tissue without any lining, along with separate keratin flakes and a small bony chip. The cystic lesion showed skin tissue lined by keratinizing squamous epithelium. The lumen had keratin flakes and a granular layer was seen. Focally, hair follicles were also present. However, no other germ cell component was seen. The features favored those of a dermoid cyst. The child made an uneventful postoperative recovery and was kept on broad-spectrum antibiotics which were then changed to specific Gram-positive coverage, extending to a full 2 weeks of administration. No new neurological deficits were noted, and she was subsequently discharged. At subsequent follow-ups, the child regained full function in both the lower limbs.

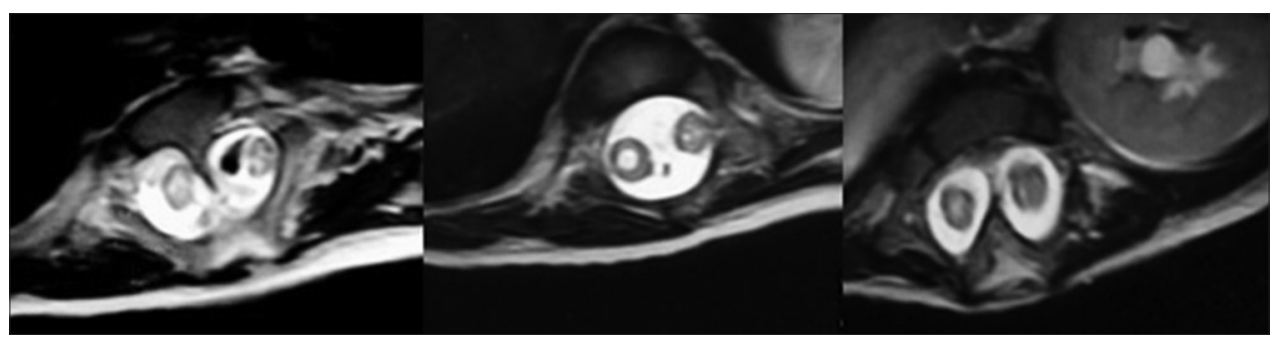

Figure 2: This sequence (axial section) shows the spinal cord as seen at T6, TI I, and TI2, respectively 
Upon completion of her antibiotic course and normalization of CRP, she was readmitted 4 weeks later for elective repair of her multilevel SCM. Both malformations were approached through a single linear midline incision, and after respective laminectomies, the bony spurs at each level were individually drilled and removed. The operative findings correlated with the MRI interpretation and in between the two Type 1 SCM, there existed a single dural sheath. The canal was spacious and no attempts were made to reconstruct the two dural

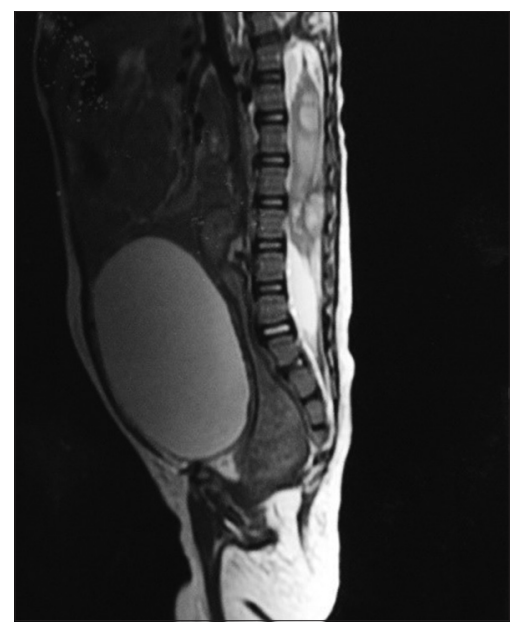

Figure 3: T2-weighted image (sagittal section) showed the presence of abscesses sheaths into one, at either level. The child once again made an uneventful recovery.

\section{DISCUSSION}

The unified theory for SCM states that it develops due to the formation of an "accessory neurenteric canal," which allows communication between the ectoderm and endoderm as stated by Pang et al..$^{[14,15]}$ The presence of such a canal leads to the separation of the notochord in that region and the presence of an endomesenchymal tract around it, results in the presence of a septum between the two cords and the lesions seen on it. ${ }^{[14,15]}$ Hence, if such canals are present at multiple levels,

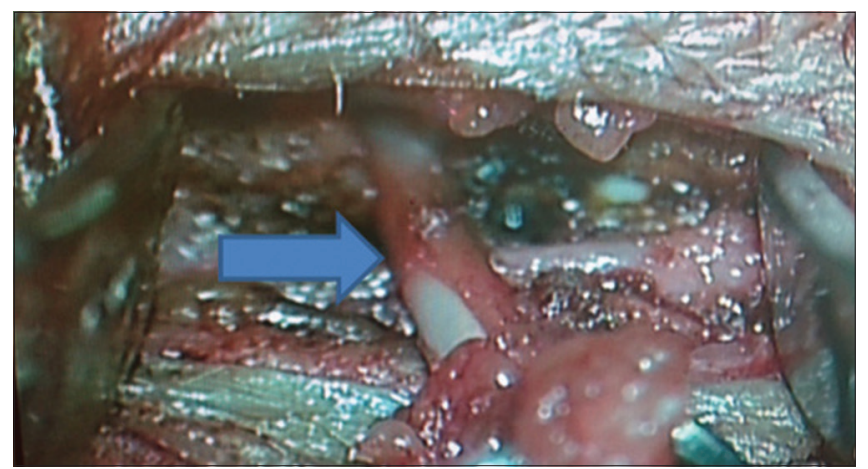

Figure 4: The dermal sinus tracts as seen intraoperatively (labeled by the blue arrow) leading to thecal sac and epidural abscess

Table 1: Review of cases with split cord malformation at multiple levels

\begin{tabular}{|c|c|c|c|c|c|}
\hline Year & $\begin{array}{l}\text { Primary } \\
\text { authors }\end{array}$ & Age/sex & Presentation & $\begin{array}{l}\text { Presence of } \\
\text { dermal sinus tract }\end{array}$ & Other features \\
\hline 2015 & Our case & 15 months/female & $\begin{array}{l}\text { High-grade fever } \\
\text { Progressive, bilateral leg weakness (for } 2 \text { weeks) } \\
\text { Power of } 3 / 5 \text { in left lower limb and } 4 / 5 \text { in the right } \\
\text { lower limb } \\
\text { Abnormal tuft of hair in the midline in the } \\
\text { mid-lumbar region }\end{array}$ & L1 & $\begin{array}{l}\text { Type } 1 \text { SCM from T4 to T6 } \\
\text { Type } 1 \text { SCM from T9 to T11 } \\
\text { Dermoid cyst }\end{array}$ \\
\hline 2012 & Singh et al. ${ }^{[17]}$ & 18 months/male & $\begin{array}{l}\text { Increasing weakness in right foot since birth } \\
\text { Clubfoot on right with power of } 3 / 5 \\
\text { Pigmented skin in upper thoracic and lower } \\
\text { lumbar region with hypertrichosis and tenderness }\end{array}$ & None & $\begin{array}{l}\text { Type } 2 \text { SCM at T2 } \\
\text { Type } 1 \text { SCM at L2 }\end{array}$ \\
\hline 2011 & $\begin{array}{l}\text { Ailawadhi and } \\
\text { Mahapatra }^{[2]}\end{array}$ & 3 years/female & $\begin{array}{l}\text { Worsening scoliosis } \\
\text { Mild weakness in left lower limb }\end{array}$ & No & $\begin{array}{l}\text { Type } 1 \text { SCM at T6, T12, } \\
\text { and L3 }\end{array}$ \\
\hline 2011 & $\begin{array}{l}\text { Khandelwal } \\
\text { et al. }{ }^{[11]}\end{array}$ & 4 years/female & $\begin{array}{l}\text { Swelling }(6 \mathrm{~cm} \times 8 \mathrm{~cm}) \text { in lower back and } \\
\text { difficulty in walking } \\
\text { Dermal sinus in coccygeal region } \\
\text { Power of } 4 / 5 \text { in lower limbs }\end{array}$ & Coccygeal region & $\begin{array}{l}\text { Thoracic nonterminal } \\
\text { myelocystocele at D7-D8 } \\
\text { Type } 2 \text { SCM at T10 } \\
\text { Type } 1 \text { SCM at L2-L3 } \\
\text { Hydrocephalus }\end{array}$ \\
\hline 2005 & Akay et al..$^{[3]}$ & 6 months/female & $\begin{array}{l}\text { Symptoms of common cold } \\
\text { Scoliosis in thoracic spine with hypertrichosis }\end{array}$ & No & $\begin{array}{l}\text { Type } 1 \text { SCM at T4 and T5 } \\
\text { Type } 2 \text { SCM at T12 }\end{array}$ \\
\hline 2001 & $\begin{array}{l}\text { Vaishya and } \\
\text { Kumarjain }^{[19]}\end{array}$ & $\begin{array}{l}30 \text { months/male } \\
16 \text { months/female } \\
30 \text { months/male }\end{array}$ & $\begin{array}{l}\text { Case 1: Severe kyphoscoliosis in dorsal region, } \\
\text { hyperpigmented patch on back, bilateral } \\
\text { increased muscle tone } \\
\text { Case 2: Scoliosis in lower thoracic region } \\
\text { Case 3: Hypertrichosis on lower back and } \\
\text { Kyphoscoliosis }\end{array}$ & No & $\begin{array}{l}\text { Case 1: Type } 2 \text { SCM at T7 } \\
\text { and T10-T11 } \\
\text { Case 2: Type } 1 \text { SCM at } \\
\text { L2-L3 and Type } 2 \text { at L5 } \\
\text { Case 3: Types } 1 \text { and } 2 \\
\text { at L1-L3 }\end{array}$ \\
\hline
\end{tabular}


it may lead to the presence of SCM at several levels, as seen in our case. DSTs are hypothesized to occur between the $3^{\text {rd }}$ and $8^{\text {th }}$ weeks of gestation. ${ }^{[8]}$ The epithelial lined tract acts as a conduit for infections, which in the case of our patient, lead to an extensive epidural abscess. ${ }^{[5]}$ There are several reports of SCM associated with one or more congenital and acquired disorders including DST. ${ }^{[7,16]}$

Our patient presented with two-level, Type I SCM along with a DST, a dermoid cyst, and an epidural abscess. Our review of literature focusing on the presence of SCM at more than one level and its presence with a DST (with or without a dermoid cyst) is summarized in Table 1.

The case series by Ackerman and Menezes reported the prevalence of DSTs as $18.5 \%$ in the cervical region, $14.8 \%$ in the thoracic region, $33 \%$ in the lumbar region, and $33 \%$ in the lumbosacral region. ${ }^{[8]}$ While in another series, Jindal and Mahapatra reported 13\% of cases in the thoracic region, $73.9 \%$ in the lumbar region, and $13 \%$ of the cases in the lumbosacral region. ${ }^{[10]}$ Despite the variation in frequency, it is clear that most cases of spinal DSTs are seen in the lumbosacral region. DSTs can further present with inclusion cysts and epidural abscesses as in our case. Consequently, a study by Thompson on inclusion cysts reported an association of $73 \%$ with DSTs. ${ }^{[18]}$ Radmanesh et al. reported dermoid cysts as being the most common associated tumor with DSTS ${ }^{[16]}$ whereas Ackerman and Menezes reported mass lesions in $50 \%$ of their cases with lipomas being the most common tumor seen. ${ }^{[1]}$ However, the case series by Mete et al. had no inclusion cysts. ${ }^{[13]}$ Overall, Pang et al. and Mahapatra and Gupta reported the presence of a DST in cases with SCM at a single level. ${ }^{[12]}$ However, SCM at various levels with a DST had not been reported in either of the two series.

On reviewing the literature, we were able to find only one case of a multilevel SCM with a DST as reported by Khandelwal et al. and six cases of composite SCM as reported by Ersahin et al. in his series of 131 cases. ${ }^{[6,7,11]}$ Out of all these cases of SCM at more than one level, only one case reported the combined presence of composite SCM, DST, and dermoid cyst. ${ }^{[6,7]}$ The child in our study also had a congenital renal anomaly. In our review of literature, no cases were screened for other congenital anomalies. $[2,3,6,7,11,17,19]$
Financial support and sponsorship

Nil.

\section{Conflicts of interest}

There are no conflicts of interest.

\section{REFERENCES}

I. Ackerman LL, Menezes AH. Spinal congenital dermal sinuses: A 30-year experience. Pediatrics 2003; I I 2 (3 Pt I):64I-7.

2. Ailawadhi P, Mahapatra AK. An unusual case of spinal dysraphism with four splits including three posterior spurs. Pediatr Neurosurg 201 1;47:372-5.

3. Akay KM, Izci Y, Baysefer A, Timurkaynak E. Composite type of split cord malformation: Two different types at three different levels: Case report. J Neurosurg 2005; 1024 Suppl: 436-8.

4. Dạmbska M,Wisniewski KE. Normal and Pathologic Development of the Human Brain and Spinal Cord I. England:John Libbey and company Ltd.; 1999.

5. De Vloo P, Lagae L, Sciot R, Demaerel P, van Loon J, Van Calenbergh F. Spinal dermal sinuses and dermal sinus-like stalks analysis of 14 cases with suggestions for embryologic mechanisms resulting in dermal sinus-like stalks. Eur J Paediatr Neurol 2013; 17:575-84.

6. Ersahin Y, Mutluer S, Kocaman S, Demirtas E. Split spinal cord malformations in children. J Neurosurg 1998;88:57-65.

7. Ersahin Y. Split cord malformation types I and II: A personal series of I3 I patients. Childs Nerv Syst 2013;29:15I5-26.

8. French BN. The embryology of spinal dysraphism. Clin Neurosurg 1983;30:295-340.

9. Hung PC, Wang HS, Wu CT, Lui TN, Wong AM. Spinal intramedullary abscess with an epidermoid secondary to a dermal sinus. Pediatr Neurol 2007;37:| 44-7.

10. Jindal A, Mahapatra AK. Spinal congenital dermal sinus: An experience of 23 cases over 7 years. Neurol India 200I;49:243-6.

II. Khandelwal A, Tandon V, Mahapatra AK. An unusual case of 4 level spinal dysraphism: Multiple composite type I and type 2 split cord malformation, dorsal myelocystocele and hydrocephalous. J Pediatr Neurosci 201 I;6:58-6I.

12. Mahapatra AK, Gupta DK. Split cord malformations: A clinical study of 254 patients and a proposal for a new clinical-imaging classification. J Neurosurg 2005; 1036 Suppl: 531-6.

13. Mete M, Umur AS, Duransoy YK, Barutçuoglu M, Umur N, Gurgen SG, et al. Congenital dermal sinus tract of the spine: Experience of 16 patients. J Child Neurol 2014;29:1277-82.

14. Pang D, Dias MS, Ahab-Barmada M. Split cord malformation: Part I: A unified theory of embryogenesis for double spinal cord malformations. Neurosurgery 1992;31:451-80.

I5. Pang D. Split cord malformation: Part II: Clinical syndrome. Neurosurgery 1992;31:48I-500.

16. Radmanesh F, Nejat F, El Khashab M. Dermal sinus tract of the spine. Childs Nerv Syst 2010;26:349-57.

17. Singh DK, Singh N, Singh R. Widely separated composite split cord malformation. BMJ Case Rep 2012;20I2. pii: Bcr20I 2007028.

18. Thompson DN. Spinal inclusion cysts. Childs Nerv Syst 2013;29:1647-55.

19. Vaishya S, Kumarjain P. Split cord malformation: Three unusual cases of composite split cord malformation. Childs Nerv Syst 200 I; 17:528-30. 